\title{
Experimental colitis alters expression of 5-HT receptors and transient receptor potential vanilloid 1 leading to visceral hypersensitivity in mice
}

\author{
Kenjiro Matsumoto ${ }^{1}$, Mee Wah Lo ${ }^{1,2}$, Takuji Hosoya ${ }^{1,3}$, Kimihito Tashima ${ }^{1}$, Hiromitsu Takayama ${ }^{2}$, \\ Toshihiko Murayama ${ }^{3}$ and Syunji Horie ${ }^{1}$
}

\begin{abstract}
Abnormalities of primary afferent nerve fibers are strongly associated with the visceral hypersensitivity state in inflammatory bowel disease. Hypersensitivity of afferent fibers occurs during inflammation. Therefore, to gain an insight into the alterations to receptors and channels expressed in primary afferent neurons, the current study aimed to investigate the time-dependent dynamic changes in levels of 5-hydroxytryptamine $(5-\mathrm{HT})_{3}$ receptors, $5-\mathrm{HT}_{4}$ receptors, transient receptor potential vanilloid type 1 (TRPV1) channels, and 5-HT regulatory factors in dextran sulfate sodium (DSS)-induced colitis model mice. 5-HT signaling molecules were detected by indirect staining with specific antibodies. TRPV1-immunoreactivity was detected by staining with fluorescein-conjugated tyramide amplification. To assess nociception, visceromotor responses (VMRs) to colorectal distension were measured by electromyography of abdominal muscles. Immunohistochemical analysis and VMRs to colorectal distention were measured during induction of DSS colitis (days 4 and 7). Inflammation led to downregulation of serotonin transporter immunoreactivities with concomitant increases in 5-HT and tryptophan hydroxylase-1-positive cell numbers. TRPV1-expressing nerve fibers gradually increased during DSS treatment. Abundant nonneuronal TRPV1-immunopositive cell-like structures were observed on day 7 of DSS treatment but not on day 4 . The number of $5-\mathrm{HT}_{3}$ receptor-expressing nerve fibers in the mucosa was increased on day 7 . On the other hand, the number of $5-\mathrm{HT}_{4}$ receptor-expressing nerve fibers in the mucosa decreased on day 7 . We made the novel observation of increased expression of neuronal/nonneuronal TRPV1 channels and 5- $\mathrm{HT}_{3}$ receptors, and decreased expression of $5-\mathrm{HT}_{4}$ receptors in the mucosa in a DSS-induced colitis model. Visceral hyperalgesia was observed on day 7 but not on day 4. A TRPV1 antagonist and a $5-\mathrm{HT}_{3}$ receptor antagonist attenuated the visceral hyperalgesia to the control level. The alterations of $5-\mathrm{HT}$ signaling via $5-\mathrm{HT}_{3}$ receptors and of TRPV1 channels in mucosa may contribute to the visceral hypersensitivity in colitis model mice.

Laboratory Investigation (2012) 92, 769-782; doi:10.1038/labinvest.2012.14; published online 13 February 2012
\end{abstract}

KEYWORDS: enteric nervous system; inflammatory bowel disease; serotonin; TRPV1; visceral hypersensitivity

Inflammatory bowel disease (IBD), encompassing ulcerative colitis and Crohn's disease, is an emerging health problem with prevalence that is rising all over the world. ${ }^{1}$ Abdominal pain and bloody diarrhea are the most common symptoms of IBD. In particular, abdominal pain lowers the quality of life in IBD patients. It appears that IBD in general modulates visceral sensitivity. ${ }^{2}$ Moreover, IBD will induce hypersensitivity $^{3}$ or hyposensitivity ${ }^{4,5}$ depending upon the degree and/ or duration of inflammation. It has been suggested that abnormalities of sensory nerve fibers are strongly associated with the visceral sensitivity in IBD patients.

Two broad classes of sensory (primary afferent) neurons are associated with the gut: intrinsic primary afferent neurons (IPANs) and extrinsic primary afferent neurons (EPANs). ${ }^{6}$ IPANs have cell bodies in the myenteric plexus and submucosal plexus. EPANs have cell bodies in nodose and jugular ganglia (vagal afferents) or in the dorsal root ganglia (spinal afferents). ${ }^{6}$ Hypersensitivity of afferent fibers occurs

${ }^{1}$ Laboratory of Pharmacology, Josai International University, Togane, Japan; ${ }^{2}$ Department of Molecular Structure and Biological Function, Graduate School of

Pharmaceutical Sciences, Chiba University, Chiba, Japan and ${ }^{3}$ Department of Chemical Pharmacology, Graduate School of Pharmaceutical Sciences, Chiba University, Chiba, Japan

Correspondence: Dr K Matsumoto, PhD, Laboratory of Pharmacology, Faculty of Pharmaceutical Sciences, Josai International University, 1 Gumyo, Togane, Chiba 283-8555, Japan.

E-mail: kenjiro@jiu.ac.jp

Received 5 August 2011; revised 16 November 2011; accepted 28 November 2011 
during inflammation, and understanding the alterations to the levels of receptors and channels expressed in afferent neurons may help explain the mechanisms underlying visceral hypersensitivity in IBD patients.

Enteric 5-hydroxytryptamine (5-HT) has a key role in sensory transduction. 5-HT can activate the endings of IPANs and EPANs within the mucosa of the large intestine. ${ }^{7}$ The majority of 5-HT is synthesized in enterochromaffin (EC) cells, which use tryptophan hydroxylase-1 (TPH-1) as their rate-limiting enzyme. ${ }^{8,9}$ The serotonin reuptake transporter (SERT) is the primary molecule responsible for terminating the actions of 5 -HT. ${ }^{10}$ The 5 -HT content in the mucosa is regulated mainly by TPH-1 and SERT. Various findings from IBD patients and experimental colitis model animals show that 5-HT has important roles in intestinal inflammation and visceral hypersensitivity. Changes in the numbers of EC cells have been reported in IBD patients. ${ }^{11-13}$ Ghia et al. ${ }^{14}$ reported decreased severity of dextran sulfate sodium (DSS)-induced colitis in TPH-1-deficient mice. SERT-deficient mice exhibit an increase in the severity of trinitrobenzene sulfonic acid (TNBS)-induced colitis, ${ }_{15}^{15}$ and SERT expression is reduced in both IBD patients ${ }^{12}$ and experimental colitis model animals. ${ }^{16,17}$ These findings strongly suggest that enteric serotonergic signaling contributes to the pathophysiology of IBD. However, no study to date has investigated the alterations in the levels of 5-HT receptors in experimental colitis animals.

5 -HT receptors have key roles in visceral sensing. ${ }^{18} 5-\mathrm{HT}_{3}$ and $5-\mathrm{HT}_{4}$ receptors are expressed in afferent neurons and have been explored as potential targets for the treatment of visceral hypersensitivity in gastrointestinal disorders. ${ }^{19}$ In fact, $5-\mathrm{HT}_{3}$ antagonists and a $5-\mathrm{HT}_{4}$ partial agonist inhibited visceral hypersensitivity in experimental colitis model rats. ${ }^{20-22}$

The transient receptor potential vanilloid type 1 (TRPV1) channel, also referred to as the capsaicin receptor, which has been described as a polymodal sensor, ${ }^{23}$ is a representative channel expressed in EPANs. It is well known that TRPV1 channels are involved in diseases associated with the hypersensitivity of the large intestine. Indeed, the numbers of TRPV1 nerve fibers in the large intestine were found to be increased in biopsies taken from patients with IBD. ${ }^{24,25}$ Interestingly, TRPV1 expression level was correlated with abdominal pain severity in IBD patients. ${ }^{24}$

5-HT can also enhance afferent responsiveness indirectly through facilitation of TRPV1 responses. 5-HT receptor activation enhances the responsiveness of the TRPV1 receptor to acid and temperature, and thereby contributes to peripheral sensitization. ${ }^{26}$ Moreover, a $5-\mathrm{HT}_{3}$ receptor antagonist attenuated capsaicin-containing red chili-induced visceral hypersensitivity in humans. ${ }^{27}$ These results suggest that 5-HT and its receptors potentially participate in the activation of TRPV1 channels in the visceral hypersensitivity state.

In this study, we hypothesized that alterations to the levels of not only 5-HT but also 5-HT receptors and TRPV1 channels contribute to visceral hypersensitivity during intestinal inflammation. The current study was designed to investigate the time-dependent dynamic changes in the levels of 5- $\mathrm{HT}$ regulatory factors, $5-\mathrm{HT}_{3}, 5-\mathrm{HT}_{4}$ receptors, and TRPV1 channels in DSS-induced colitis model mice. To gain further insight into the relationship between these changes and visceral hypersensitivity in the inflammatory state, we assessed visceromotor responses (VMRs) to colorectal distention (CRD) using selective antagonists.

\section{MATERIALS AND METHODS \\ Animals}

We used male C57BL/6J mice (Charles River Japan, Yokohama, Japan) aged 9-10 weeks. Animals were housed in a temperature-controlled room at $24^{\circ} \mathrm{C}$ with lights on from 0700 to 1900 hours and free access to food and water. All experiments were performed in compliance with the 'Guiding Principles for the Care and Use of Laboratory Animals' approved by the Japanese Pharmacological Society and the guidelines approved by the Institutional Animal Care and Use Committee of Josai International University, and committee approval was obtained. The number of animals used was kept to the minimum necessary for a meaningful interpretation of the data and animal discomfort was kept to the minimum.

\section{Induction and Evaluation of DSS Colitis}

Colitis was induced by the addition of $3 \%(\mathrm{wt} / \mathrm{vol})$ DSS (molecular weight $36-50 \mathrm{kDa}$; MP Biomedicals, Irvine, CA, USA) to the drinking water. The disease activity index and histological damage were assessed by trained individuals blinded to the treatment groups as reported previously. ${ }^{28,29}$

\section{Determination of 5-HT Level}

5-HT content in the rectum was analyzed by enzyme immunoassay using a commercially available kit (Beckman Coulter, Fullerton, CA, USA) as previously reported. ${ }^{14}$

\section{Assessment of VMR to CRD}

As a visceral stimulus, mechanical distensions of the rectum were performed by pressure-controlled air inflation of a $2-\mathrm{cm}$ flexible polyethylene balloon connected to an electronic distension device (Distender Series II barostat, G\&J Electronics, Willowdale, ON, Canada). The balloon was lubricated, inserted intra-anally and positioned $5 \mathrm{~mm}$ proximal to the anus. When the balloon is inflated, it mainly touches the rectal area corresponding to the area used for immunohistochemical study. The VMR to CRD was quantified by electromyographic (EMG) recordings of abdominal wall muscle activity. Mice were challenged with distending pressures of 15, 30, 45, and $60 \mathrm{mmHg}$, with two 10-s trials at each pressure and a 2-min recovery period between distensions. Data were imported into 8-channel analyzer software (Starmedical, Tokyo, Japan) for analysis. 
Two groups of mice received i.p. administration of vehicle (20\% hydroxypropyl- $\beta$-cyclodextrin) or the TRPV1 antagonist $N$-(4-tertiary butylphenyl)-4-(3-chloropyridin-2-yl) tetrahydropyrazine-1(2H)-carbox-amide (BCTC) $(20 \mathrm{mg} / \mathrm{kg})$ $60 \mathrm{~min}$ before CRD. Two groups of mice received p.o. administration of vehicle ( $0.3 \%$ carboxyl methyl cellulose) or the $5-\mathrm{HT}_{3}$ antagonist alosetron $(3 \mathrm{mg} / \mathrm{kg}) 30 \mathrm{~min}$ before CRD. All drugs and vehicle were given in a volume of $0.1 \mathrm{ml} /$ $10 \mathrm{~g}$ body weight.

\section{Immunohistochemistry}

Tissue preparation and immunohistochemical procedures were performed as described by Matsumoto et al. ${ }^{30,31}$ Sources of all primary and secondary antibodies, as well as the optimized dilutions, are listed in Tables 1 and 2. TRPV1 immunoreactivity was detected using the fluoresceinconjugated tyramide amplification method. Other molecules were detected by indirect staining with specific antibodies. No specific immunostaining could be observed in control experiments. The specificities of TRPV1 channels, $5-\mathrm{HT}_{3}$ receptors, and $5-\mathrm{HT}_{4}$ receptors are shown by loss of immunostaining when the primary antibody was preadsorbed with the corresponding antigen peptide.

\section{Microscopy and Image Analysis}

Sections were viewed using a confocal microscope (FV-1000, Olympus, Tokyo, Japan) and images were captured using Olympus Fluoview ver 1.7a. software.

For quantitative analysis, sections were viewed at $\times 20$ magnification using a confocal microscope with an excitation wavelength appropriate for FITC. Determinations were made from three random locations in each mouse $(n=4-6)$. The numbers of 5-HT-, TPH-1- and substance P-immunopositive cells and the numbers of TRPV1-, 5- $\mathrm{HT}_{3}$ receptor-, 5- $\mathrm{HT}_{4}$ receptor-, and substance $\mathrm{P}$-immunopositive nerve fibers were counted and normalized to the length of the muscularis mucosa $(0.5 \mathrm{~mm})$. For quantitative analysis of the SERTimmunopositive area, after interactive thresholding, the active areas were measured using an image analysis system (Olympus Fluoview ver 1.7a software), converted to the number of pixels in a set area $\left(\mu \mathrm{m}^{2}\right)$, and normalized to a predetermined length of muscularis mucosa $(0.5 \mathrm{~mm})$.

\section{Statistical Analysis}

Data are expressed as mean \pm s.e.m. Statistical analyses were performed by a Bonferroni multiple comparison test for comparisons of more than two groups. A $P$-value $<0.05$ was considered statistically significant.

\section{RESULTS}

Localization of TRPV1 Channels, 5-HT 3 Receptors, $5-\mathrm{HT}_{4}$ Receptors, and their Colocalization with 5-HT in Mouse Rectum in the Physiological State

We performed double-labeling experiments using transverse and horizontal sections of mucosa and the muscle layers of mouse rectum. In transverse sections of mucosa, abundant TRPV1 nerve fibers were observed (Figure 1a), whereas $5-\mathrm{HT}_{3}$ and $5-\mathrm{HT}_{4}$ receptor immunoreactivities were identified not only within nerve fibers but also in cell-like structures in the mucosa (arrow; Figure 1b and c). In horizontal sections of mucosa, TRPV1-, 5- $\mathrm{HT}_{3-}^{-}$, and $5-\mathrm{HT}_{4}{ }^{-}$ immunopositive nerve fibers were identified in the lamina propria surrounding mucosal crypts (Figure 1d-f). Doublelabeling showed that TRPV1-immunopositive nerve fibers,

\section{Table 2 Secondary antibody used}

\begin{tabular}{llll}
\hline Secondary antibody & Conjugate probe & Dilution & Source \\
\hline Donkey anti-rabbit lgG & Biotin-SP & $1: 400$ & Jackson \\
Donkey anti-rabbit lgG & FITC & $1: 400$ & Jackson \\
Donkey anti-rabbit lgG & TRITC & $1: 400$ & Jackson \\
Donkey anti-guinea-pig lgG & TRITC & $1: 400$ & Jackson \\
Donkey anti-sheep IgG & TRITC & $1: 400$ & Jackson \\
Donkey anti-goat lgG & TRITC & $1: 400$ & Jackson \\
\hline
\end{tabular}

Table 1 Primary antibody used

\begin{tabular}{|c|c|c|c|}
\hline Antigen & Host & Dilution & Source \\
\hline TRPV1 & Rabbit & $1: 20000$ & Neuromics \\
\hline $5-\mathrm{HT}$ & Goat & 1:2000 for muscle, 1:16000 for mucosa & Immunostar \\
\hline 5- $\mathrm{HT}_{3}$ receptor & Rabbit & $1: 50$ & Calbiochem \\
\hline $5-\mathrm{HT}_{4}$ receptor & Rabbit & $1: 400$ for muscle, 1:1000 for mucosa & Abcam \\
\hline SERT & Guinea-pig & $1: 3000$ & Millipore \\
\hline $\mathrm{TPH}-1$ & Rabbit & $1: 1000$ & Millipore \\
\hline NeuN & Mouse & $1: 1000$ & Millipore \\
\hline Substance P & Guinea-pig & $1: 4000$ & Abcam \\
\hline CGRP & Sheep & $1: 2000$ & BIOMOL \\
\hline TNF- $\alpha$ & Goat & $1: 150$ & R\&D Systems \\
\hline
\end{tabular}



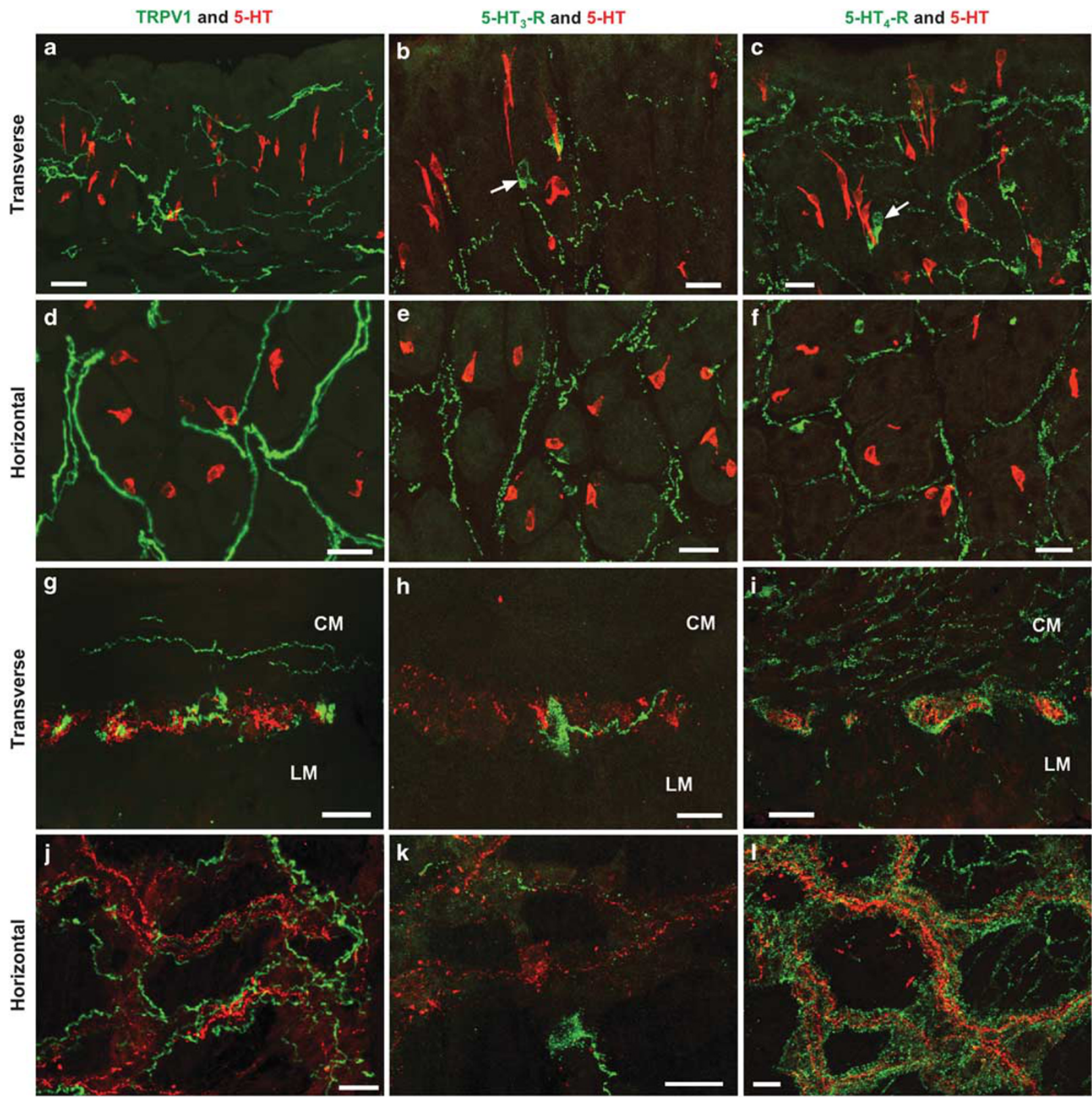

Figure 1 Confocal merged images showing localization of TRPV1 and 5- $\mathrm{HT}(\mathbf{a}, \mathbf{d}, \mathbf{g}, \mathbf{j}), 5-\mathrm{HT}_{3}$-receptors $\left(5-\mathrm{HT}_{3}-\mathrm{R}\right)$ and 5- $\mathrm{HT}(\mathbf{b}, \mathbf{e}, \mathbf{h}, \mathbf{k})$, and 5- $\mathrm{HT}_{4}$-receptors $(5-$ $\left.\mathrm{HT}_{4}-\mathrm{R}\right)$ and $5-\mathrm{HT}(\mathbf{c}, \mathbf{f}, \mathbf{i}, \mathbf{I})$ in the mucosa $(\mathbf{a}-\mathbf{f})$ and muscle layers $(\mathbf{g}-\mathbf{I})$ in the mouse rectum. Mouse rectal transverse and horizontal sections were doublelabeled for TRPV1, 5- $\mathrm{HT}_{3}-\mathrm{R}$, or 5- $\mathrm{HT}_{4}-\mathrm{R}$ (green) and 5-HT (red). TRPV1 immunoreactivities are found in the (a) mucosa, (g) circular muscle, myenteric plexus, and longitudinal muscle. (d, j) Show TRPV1 and 5-HT immunoreactivities in horizontal sections of the middle mucosa and myenteric plexus, respectively. TRPV1 nerve fibers do not colocalize with $5-\mathrm{HT}$ in the mucosa and muscle layer. $5-\mathrm{HT}_{3}-\mathrm{R}$ immunoreactivities are found in (b) mucosa and (h) myenteric plexus. (e, k) Show $5-\mathrm{HT}_{3}-\mathrm{R}$ and $5-\mathrm{HT}$ immunoreactivities in horizontal sections of the middle mucosa and myenteric plexus, respectively. $5-\mathrm{HT}_{3}{ }^{-}$ immunopositive cell-like structures and cell bodies are observed in (b) mucosa and (h, $\mathbf{k}$ ) myenteric plexus. $5-\mathrm{HT}_{3}-\mathrm{R}$ immunoreactivities do not colocalize with $5-\mathrm{HT}$ in the mucosa and muscle layer. $5-\mathrm{HT}_{4}-\mathrm{R}$ immunoreactivities are found in (c) mucosa, (i) circular muscle, myenteric plexus, and longitudinal muscle. (f, I) Show 5- $\mathrm{HT}_{4}-\mathrm{R}$ and $5-\mathrm{HT}$ in horizontal sections of middle mucosa and myenteric plexus, respectively. 5- $\mathrm{HT}_{4}$-immunopositive cell-like structures and cell bodies are observed in (c) mucosa and (I) myenteric plexus, respectively. 5- $\mathrm{HT}_{4}-\mathrm{R}$ immunoreactivities do not colocalize with 5-HT in mucosa and muscle layers. CM, circular muscle; LM, longitudinal muscle. Scale bars are $40 \mu \mathrm{m}(\mathbf{a}-\mathbf{c}, \mathbf{g}-\mathbf{i})$ and $20 \mu \mathrm{m}(\mathbf{d}-\mathbf{f}, \mathbf{j}-\mathbf{I})$.

5- $\mathrm{HT}_{3}$ - and $5-\mathrm{HT}_{4}$-immunopositive cell-like structures, and nerve fibers were not colocalized with 5-HT-immunopositive cell but rather showed an adjacent localization (Figure la-f).
In muscle layers, TRPV1-immunoreactive nerve fibers were found in the myenteric plexus and circular and longitudinal muscles (Figure 1g). Only a few 5- $\mathrm{HT}_{3}-$ 
immunoreactive neurons were identified in the myenteric plexus (Figure 1h). Abundant 5- $\mathrm{HT}_{4}$-immunoreactive neurons were observed throughout the muscle layer (Figure 1i). In the myenteric plexus, a dense network of TRPV1-immunopositive nerve fibers and $5-\mathrm{HT}_{4}$ receptorimmunopositive neurons were identified (Figure $1 \mathrm{j}$ and $\mathrm{l}$ ), but $5-\mathrm{HT}_{3}$ receptor-immunopositive neurons were sparsely dispersed (Figure 1k). Double-labeling showed that TRPV1immunopositive nerve fibers and $5-\mathrm{HT}_{3^{-}}$and $5-\mathrm{HT}_{4}{ }^{-}$ immunopositive neurons were not colocalized with 5-HT staining in the myenteric plexus (Figure $1 \mathrm{~g}-1$ ).

\section{Colocalization Studies of $5-\mathrm{HT}_{3}$ and $5-\mathrm{HT}_{4}$ Receptors, with NeuN, Substance $P$, and CGRP in Mouse Rectum in the Physiological State}

Next, we performed double-labeling experiments with NeuN or substance $\mathrm{P}$ in transverse sections of muscle layer in the mouse rectum. Double-labeling showed that $5-\mathrm{HT}_{3}$ and $5-\mathrm{HT}_{4}$ receptor-immunopositive cell bodies in the myenteric plexus expressed NeuN (Figure 2a and b). 5- $\mathrm{HT}_{3}-$ immunopositive neurons emerged from the myenteric plexus, running to the submucosal layer where $5-\mathrm{HT}_{3}-$ immunopositivity was colocalized with substance P (Figure 2c). Abundant 5- $\mathrm{HT}_{4}$-immunoreactive nerve fibers and cell bodies were strongly colocalized with substance $\mathrm{P}$ staining in muscle layers (Figure 2d).

We then performed double-labeling experiments using selective antibodies against CGRP and substance $\mathrm{P}$ in horizontal sections of mucosa (Figure $2 \mathrm{e}-\mathrm{h}$ ). $5-\mathrm{HT}_{3}$ receptorimmunoreactive nerve fibers colocalized with CGRP and substance $\mathrm{P}$ staining in mucosa (Figure $2 \mathrm{e}$ and g). $5-\mathrm{HT}_{3}$ receptor-immunopositive nerve fibers, not colocalized with CGRP or substance $\mathrm{P}$ staining, were also observed (Figure $2 \mathrm{e}$ and g). $5-\mathrm{HT}_{4}$ receptor-immunoreactive nerve fibers were highly colocalized with CGRP and substance P staining in the mucosa (Figure 2F and $\mathrm{h}$ ).

\section{DSS-Induced Colitis Alters 5-HT-Positive Cell Number, TPH1-Positive Cell Number, SERT Area, and 5-HT Content}

Mice were treated with 3\% DSS in their drinking water for 7 days. Following DSS treatment, weight loss, appearance of bloody stool, and changes in stool quality were evident by day 4 and peaked at about day 7 (Supplementary Figure $1 \mathrm{~A}, \mathrm{~B})$.

We investigated the numbers of 5-HT- and TPH-1immunopositive cells, the SERT-immunopositive area, and the amounts of $5-\mathrm{HT}$ in mice treated with $3 \%$ DSS for 0,4 and 7 days. We found a significantly higher number of 5-HTand TPH-1-immunopositive cells on day 7 compared with day 0 (Figure $3 \mathrm{a}$ and $\mathrm{b}$ ). On the other hand, the SERTimmunopositive area gradually decreased during DSS treatment; a significant decrease was detected on days 4 and 7 compared with day 0 (Figure 3c). Consistent with SERT depletion, we also observed significantly higher amounts of 5-HT in mice treated with DSS for 4 and 7 days (Figure 3d).

\section{DSS-Induced Colitis Alters Expression of TRPV1 Channels and Substance $P$ in Mouse Mucosa}

Figure 4 shows the localization of TRPV1 channels (A-C) and the numbers of TRPV1 nerve fibers (D) in the rectal mucosa of mice treated with DSS for 0,4 and 7 days. The number of the TRPV1 nerve fibers gradually increased during DSS treatment. A significant two-fold increase in the number of TRPV1-expressing nerve fibers in the mucosa was observed on day 7. Interestingly, nonneuronal TRPV1immunopositive cells were clearly observed on day 7 but not on days 0 and 4 .

In order to validate their quantitative immunohistochemical analysis, we investigated the TRPV1 channels with a Western blot analysis. As a result, we failed to detect the reproducible bands of TRPV1 channels. The epitope for the antibody may be denatured by the process of sample preparation.

Next, we investigated the alteration of substance P in DSStreated mice. The number of substance $P$ nerve fibers did not change, but the number of substance P-immunopositive cells was drastically increased in the mucosa of DSS-treated mice by day 7 (Figure $5 \mathrm{a}$ and $\mathrm{b}$ ). Substance P-immunopositive cells were entirely colocalized with 5 -HT in the mucosa of DSStreated mice on day 7 (Figure $5 \mathrm{c}-\mathrm{e}$ ). We then performed double-labeling experiments for TRPV1 with 5-HT (Figure $5 \mathrm{f}-\mathrm{h}$ ), substance $\mathrm{P}$ (Figure $5 \mathrm{i}-\mathrm{k}$ ), and tumor necrosis factor (TNF)- $\alpha$ (Figure 5l-n). TRPV1-immunoreactive nerve fibers colocalized with substance $\mathrm{P}$ in the mucosa of DSS-treated mice on day 7 (Figure 5h). Nonneuronal and neuronal TRPV1 immunoreactivities appeared adjacent to substance P- and 5-HT-immunopositive cells but no colocalization was seen (Figure $5 \mathrm{~h}$ and $\mathrm{k}$ ). Some nonneuronal TRPV1-immunopositive cells colocalized with TNF- $\alpha$-immunopositive cells (Figure 5n).

\section{DSS-Induced Colitis Increases 5- $\mathrm{HT}_{3}$ Receptor- but Decreases 5-HT 4 Receptor-Immunopositive Nerve Fibers in Mouse Mucosa}

During DSS treatment, numbers of $5-\mathrm{HT}_{3}$ receptor-positive nerve fibers tended to be increased in the rectal mucosa (Figure 6a-d). We observed a significantly higher number of $5-\mathrm{HT}_{3}$ receptor-immunopositive nerve fibers in the mucosa of DSS-treated mice on day 7 compared with day 0 (Figure $6 \mathrm{~d})$. On the other hand, the number of $5-\mathrm{HT}_{4}$ receptor-immunopositive nerve fibers gradually decreased during DSS treatment (Figure $7 \mathrm{a}-\mathrm{d}$ ) and a significant $60 \%$ decrease in the number of $5-\mathrm{HT}_{4}$ receptor-immunopositive nerve fibers was found on day 7 compared with day 0 (Figure $7 \mathrm{~d}$ ). In the muscle layers, the distribution and localization of $5-\mathrm{HT}_{3}$ and $5-\mathrm{HT}_{4}$ receptor-immunopositive neurons was not altered by DSS treatment (data not shown). 
5-HT3-R
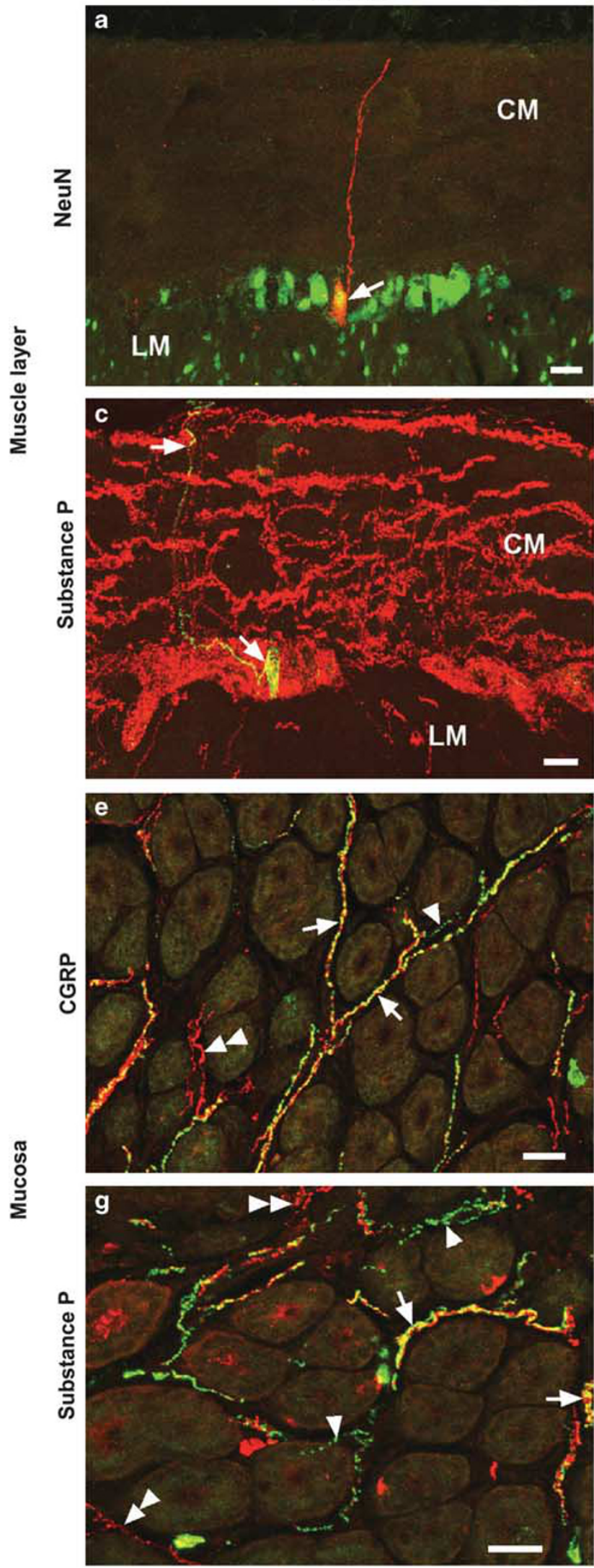

5-HT4-R
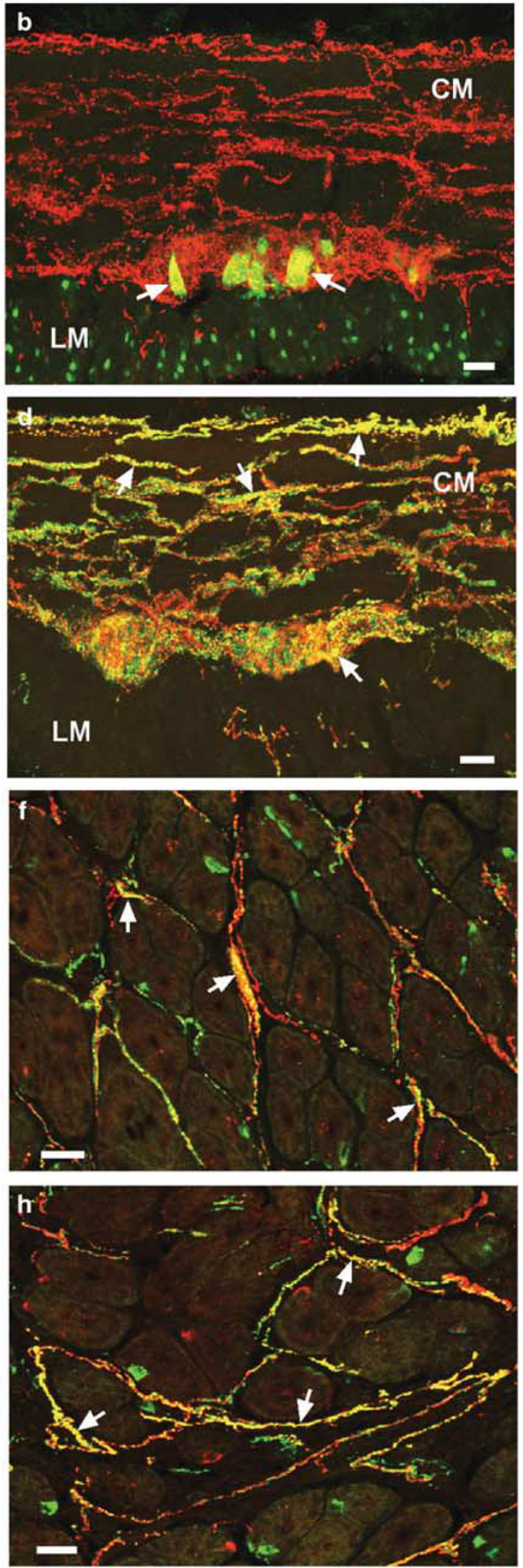
a
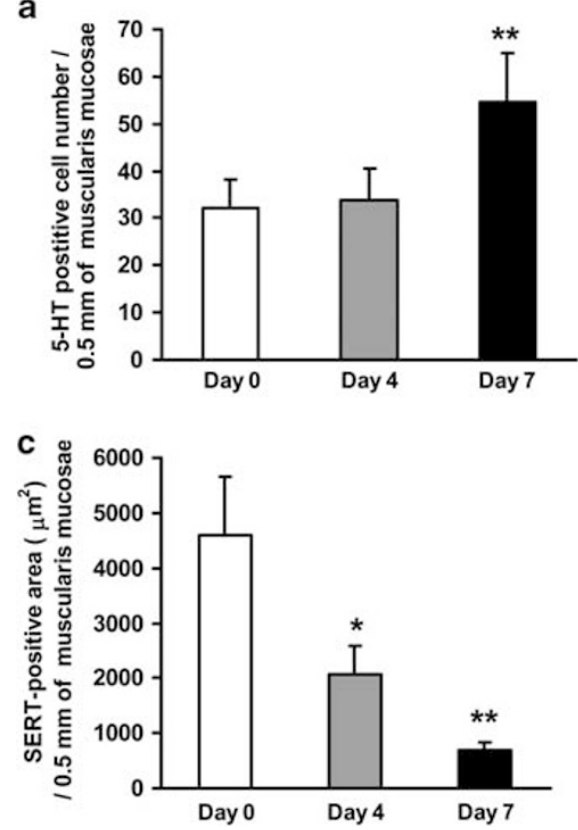
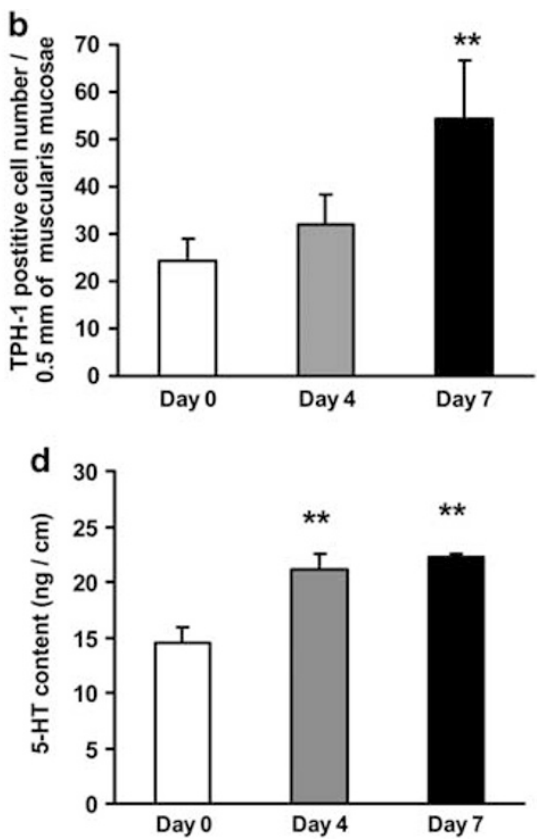

Figure 3 DSS-induced colitis alters 5-HT, TPH-1, and SERT expression in the mouse rectum. The numbers of (a) 5-HT- and (b) TPH-1-immunopositive cells increased, but SERT-immunopositive areas decreased in the mucosa of DSS-treated mice (c). (d) 5-HT content in the rectal area of mice treated with DSS for 4 or 7 days. On days 4 and 7, 5-HT content is significantly higher compared with that in mice before treatment with DSS. The asterisk (*) denotes values that are significantly different from the data on day 0 by Bonferroni correction $(* * P<0.01)$.

In order to validate their quantitative immunohistochemical analysis, we investigated the $5-\mathrm{HT}_{3}$ and $5-\mathrm{HT}_{4}$ receptors with a Western blot analysis. As a result, we failed to detect reproducible bands of $5-\mathrm{HT}_{3}$ and $5-\mathrm{HT}_{4}$ receptors. The epitope for the antibody may be denatured by the process of sample preparation.

Inflammatory cells extending into submucosal layers were observed in animals treated with DSS for 7 days (Supplementary Figure 1C). 5- $\mathrm{HT}_{4}$ immunoreactivity also decreased in the submucosal layer in DSS-treated mice on day 7. There was no clear change in the numbers of $5-\mathrm{HT}_{4}$ receptorimmunopositive cell bodies located in the myenteric plexus of DSS-treated mice. To investigate submucosal changes in $5-\mathrm{HT}_{4}$ receptor immunoreactivity, we analyzed the numbers of $5-\mathrm{HT}_{4}$ receptor-immunopositive neurons in the submucosal layer in DSS-treated mice (Figure $7 \mathrm{~g}$ ). The number of 5- $\mathrm{HT}_{4}$ receptor-immunopositive axons emerging from cell bodies was drastically decreased during DSS treatment, and a significant decrease was observed by day 7 compared with day 0 (Figure $7 \mathrm{e}-\mathrm{g}$ ).

\section{Administration of the TRPV1 Antagonist BCTC and the $5-\mathrm{HT}_{3}$ Receptor Antagonist Alosetron Inhibits DSS-Induced Visceral Hypersensitivity}

The VMR to CRD was significantly increased in mice treated with DSS for 7 days compared with vehicle-treated mice, indicating the development of visceral hyperalgesia on day 7 of DSS treatment (Supplementary Figure 1D, E). There was no significant difference in EMG responses in mice treated with DSS for 4 days compared with the vehicle-treated group.

We next investigated the potential therapeutic effect of the TRPV1 antagonist BCTC and the $5-\mathrm{HT}_{3}$ antagonist alosetron against visceral hypersensitivity induced by 7 days of DSS treatment. The TRPV1 antagonist BCTC $(20 \mathrm{mg} / \mathrm{kg}$, i.p. $)$ significantly decreased DSS-induced increases in the VMR to $\mathrm{CRD}$ at 45 and $60 \mathrm{mmHg}$ (Figure $8 \mathrm{a}$ ). The $5-\mathrm{HT}_{3}$ antagonist

Figure 2 Characterization of $5-\mathrm{HT}_{3}$ and $5-\mathrm{HT}_{4}$ receptor-immunopositive nerve fibers in the mouse rectum in the physiological state. Double-labeling of NeuN (green) with (a) 5- $\mathrm{HT}_{3}$ receptors (red) and with (b) $5-\mathrm{HT}_{4}$ receptors (red) in transverse sections of muscle layers. 5- $\mathrm{HT}_{3}$ and 5- $\mathrm{HT}_{4}$ receptorimmunopositive cell body-like structures colocalized with NeuN-immunopositive cell body in the myenteric plexus (arrows). Double-labeling of substance $\mathrm{P}$ (red) with (c) $5-\mathrm{HT}_{3}$ receptors (green) and (d) $5-\mathrm{HT}_{4}$ receptors (green) in transverse sections of muscle layers. Arrows indicate the colocalization of 5- $\mathrm{HT}_{3}$ or $5-\mathrm{HT}_{4}$ receptors with substance $\mathrm{P}$ in double-labeled neurons. Double-labeling of CGRP (red) with (e) $5-\mathrm{HT}_{3}$ receptors (green) and with (f) $5-\mathrm{HT}_{4}$ receptors (green) in horizontal sections of mucosa. Double-labeling of substance $\mathrm{P}$ (red) with (g) $5-\mathrm{HT}_{3}$ receptors (green) and with (h) $5-\mathrm{HT}_{4}$ receptors (green) in horizontal sections of mucosa. Arrows indicate the $5-\mathrm{HT}_{3}$ and $5-\mathrm{HT}_{4}$ receptor-immunopositive nerve fibers colocalized with $\mathrm{CGRP}$ - or substance $\mathrm{P}$ immunopositive nerve fibers. Arrowheads indicate $5-\mathrm{HT}_{3}$ receptor-immunopositive nerve fibers not colocalized with CGRP or substance P. Double arrowheads indicate CGRP- or substance P-immunopositive nerve fibers not colocalized with $5-\mathrm{HT}_{3}$ receptor immunopositive-nerve fibers. $\mathrm{CM}$, circular muscle; LM, longitudinal muscle. Scale bars are $10 \mu \mathrm{m}(\mathbf{a}-\mathbf{d})$ and $20 \mu \mathrm{m}(\mathbf{e}-\mathbf{h})$. 
alosetron ( $3 \mathrm{mg} / \mathrm{kg}$, p.o.) significantly decreased DSS-induced increases in the VMR to CRD at $60 \mathrm{mmHg}$ (Figure 8b). No significant effects of BCTC or alosetron were observed on the VMR to CRD at all pressures examined in control mice.

\section{DISCUSSION}

In this study, we first performed a comprehensive analysis of the dynamic changes to the levels of 5-HT regulatory factors, $5-\mathrm{HT}_{3}$ receptors, $5-\mathrm{HT}_{4}$ receptors, and TRPV1 channels in the rectal mucosa of mice in the inflammatory state. We observed increased expression of neuronal/nonneuronal TRPV1 channels and $5-\mathrm{HT}_{3}$ receptors, and decreased expression of $5-\mathrm{HT}_{4}$ receptors, in DSS-induced colitis model mice. TRPV1 antagonist and $5-\mathrm{HT}_{3}$ receptor antagonist attenuated the visceral hyperalgesia to control level in DSSinduced colitis model.

First, we investigated time-dependent changes in the levels of 5-HT regulatory factors using quantitative
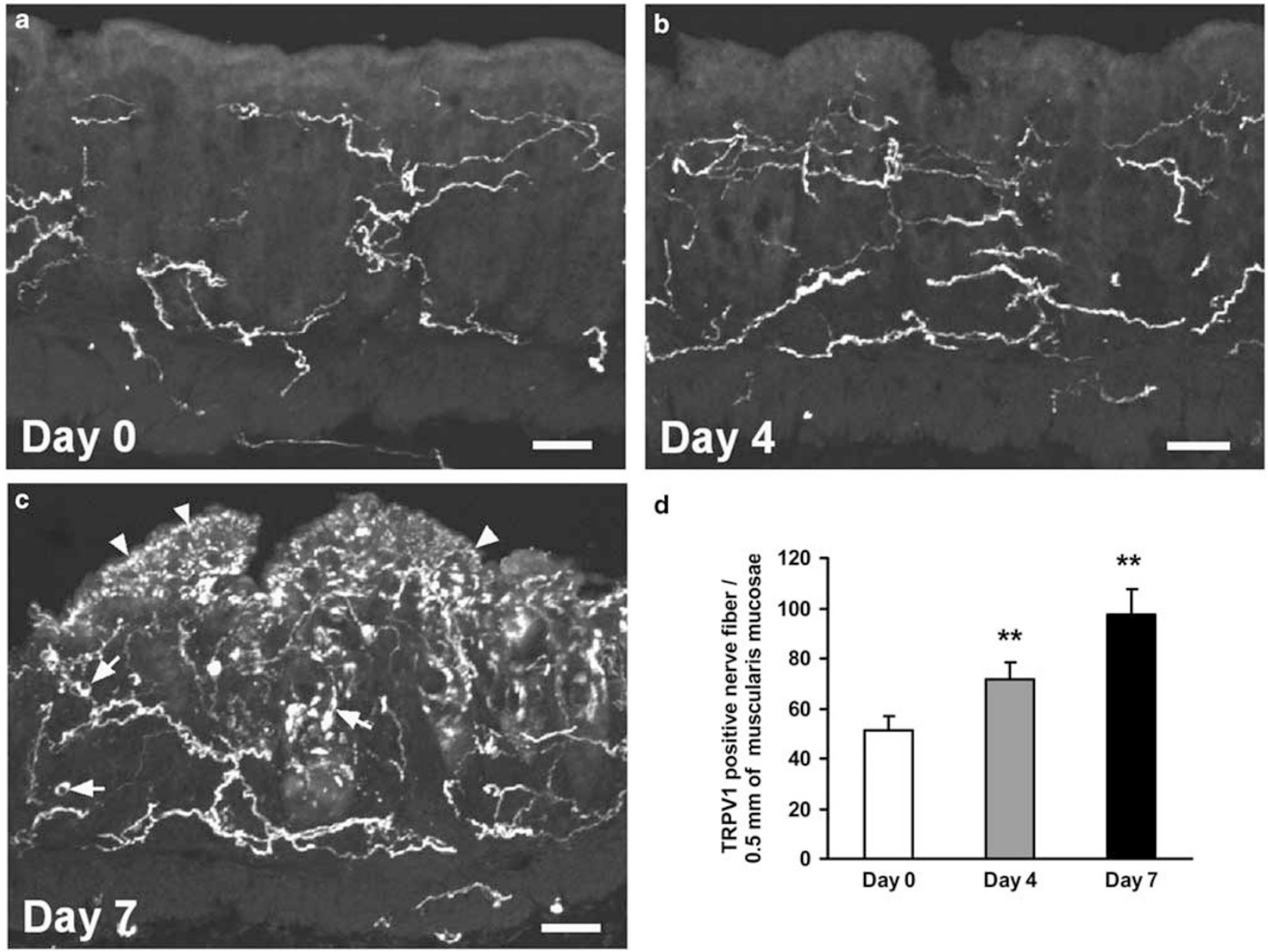

d

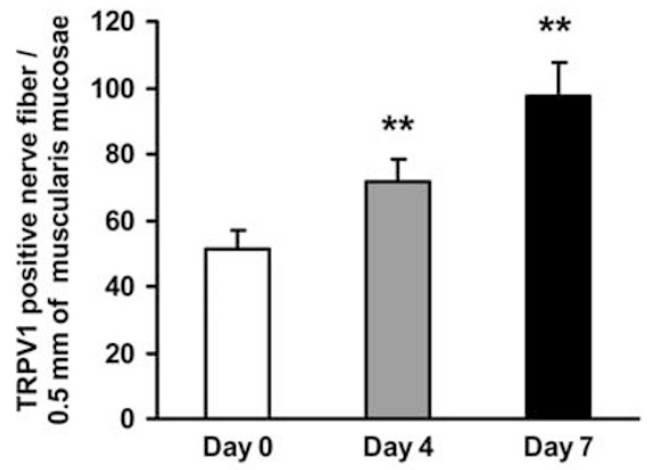

Figure 4 Mucosal TRPV1 nerve fiber immunoreactivities increased in DSS-induced colitis model mouse rectum. Confocal images showing localization of TRPV1 immunoreactivity in the mucosa of mice treated with DSS for (a) 0 , (b) 4 , and (c) 7 days. (c) Nonneuronal TRPV1-immunopositive cells were observed in epithelia (arrowhead) on day 7. (d) The numbers of TRPV1-immunopositive nerve fibers were increased in the mucosa of DSS-treated mice. The asterisk $\left(^{*}\right)$ denotes values that are significantly different from the data on day 0 by Bonferroni correction $(* * P<0.01)$. Scale bars are $40 \mu \mathrm{m}$.

Figure 5 (a) Numbers of mucosal substance P-immunopositive cells increased in DSS-induced colitis model mouce rectum. (b) Numbers of mucosal substance P-immunopositive nerve fibers did not change by day 7 . The asterisk $\left.{ }^{*}\right)$ denotes values that are significantly different from the data on day 0 by Student's $t$-test $(* * P<0.01)$. Confocal images showing localization of substance P and 5-HT (c-e), TRPV1 and substance P (f-h), TRPV1 and 5-HT (i-k), and TRPV1 and TNF- $\alpha(\mathbf{I}-\mathbf{n})$ in the mucosa of mice treated with DSS for 7 days. (e) Double-labeling image of substance P (green) with 5-HT (red) shows a substance P-immunopositive cell completely colocalized with a 5-HT-immunopositive cell in the mucosa (arrow). (h) Double-labeling image of TRPV1 (green) with substance P (red) showing a substance P-immunopositive cell not colocalized with TRPV1-immunopositive nerve fibers or cell-like structures in the mucosa. (k) Double-labeling image of TRPV1 (green) with 5-HT (red) showing 5-HT immunopositive cells not colocalized with TRPV1-immunopositive nerve fibers and cell-like structures in the mucosa. (n) Double-labeling image of TRPV1 (green) with TNF- $\alpha$ (red) showing some nonneuronal TRPV1immunopositive cells colocalized with TNF- $\alpha$-immunopositive cells in the mucosa. Scale bars are $40 \mu \mathrm{m}$. 
a

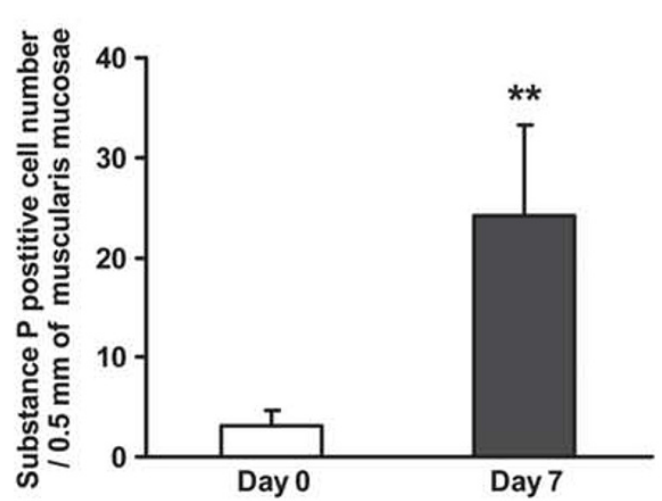

b

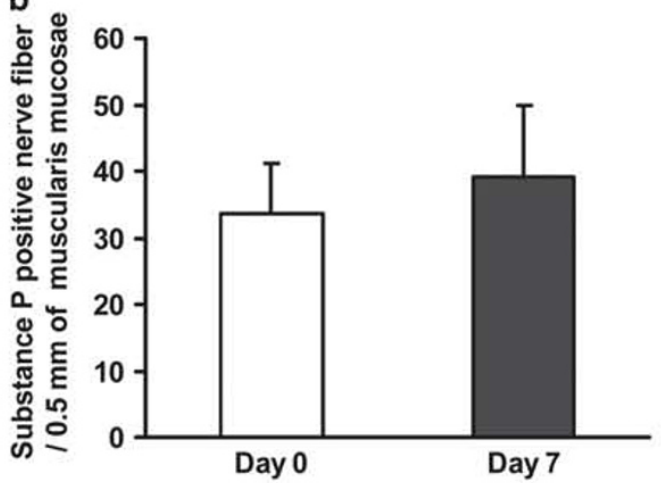

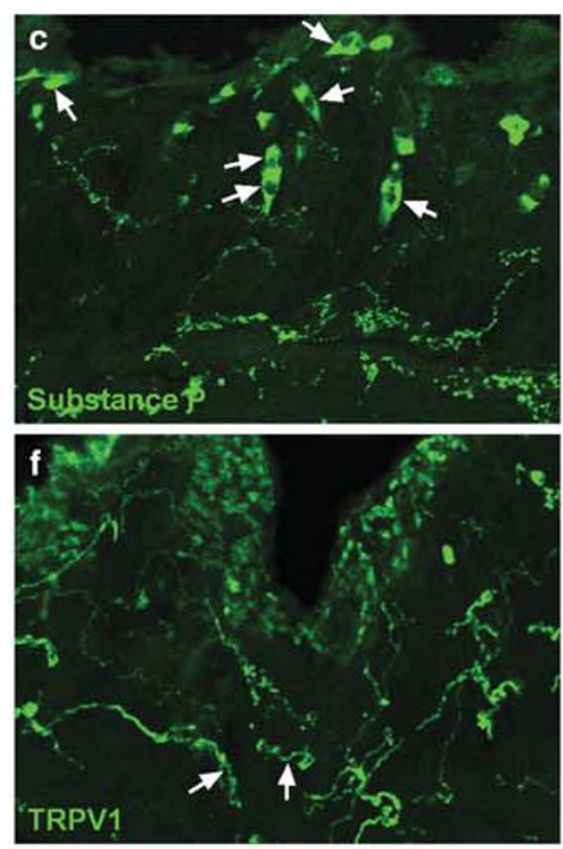

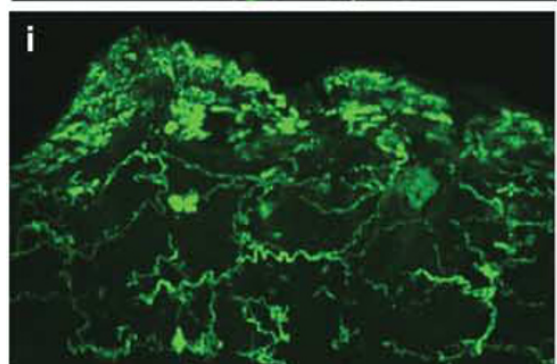

TRPV1

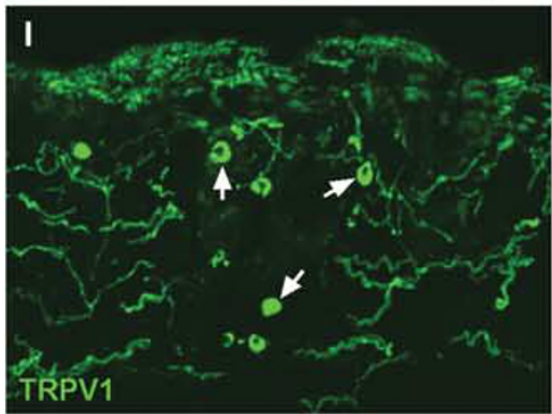

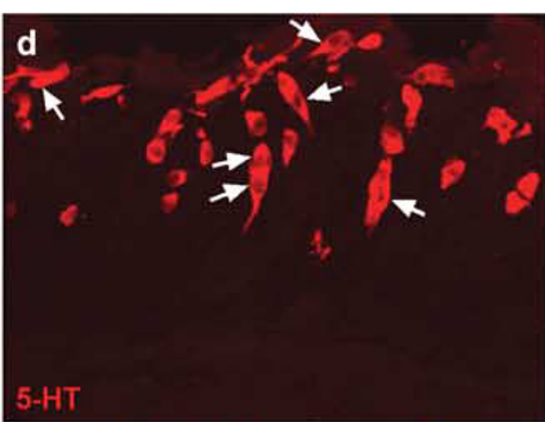
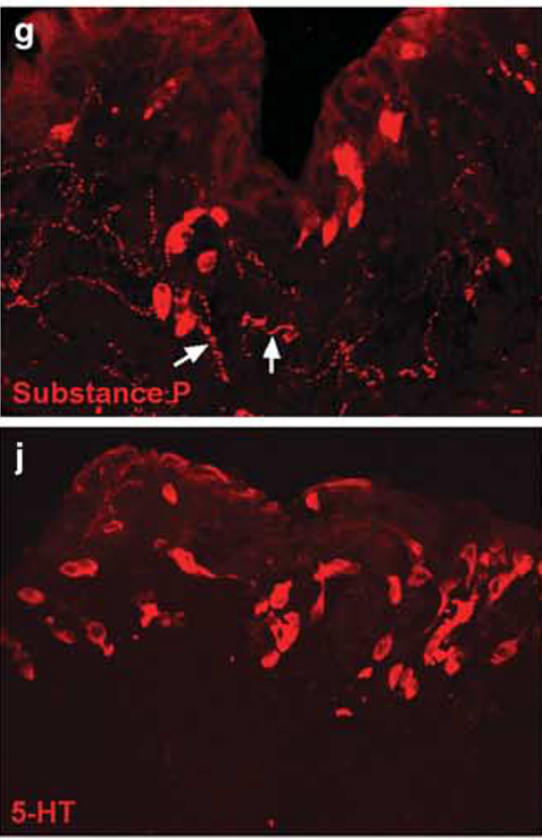

m

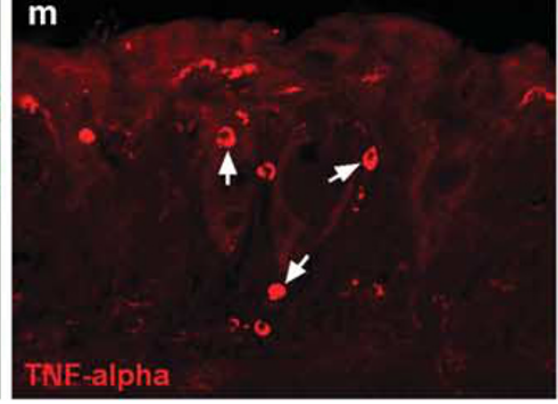

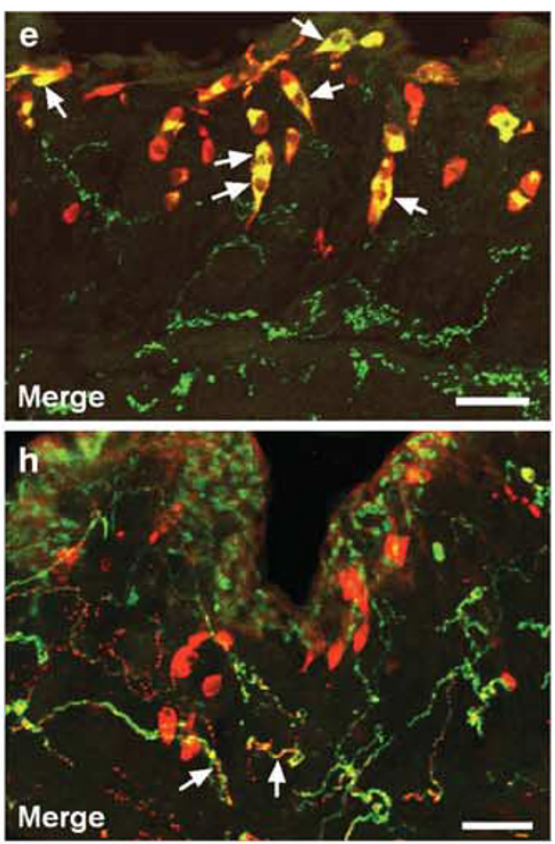
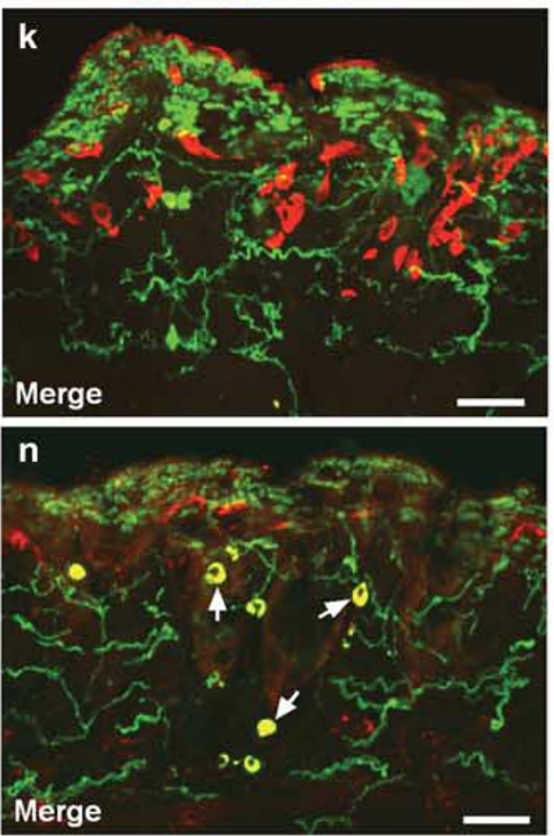

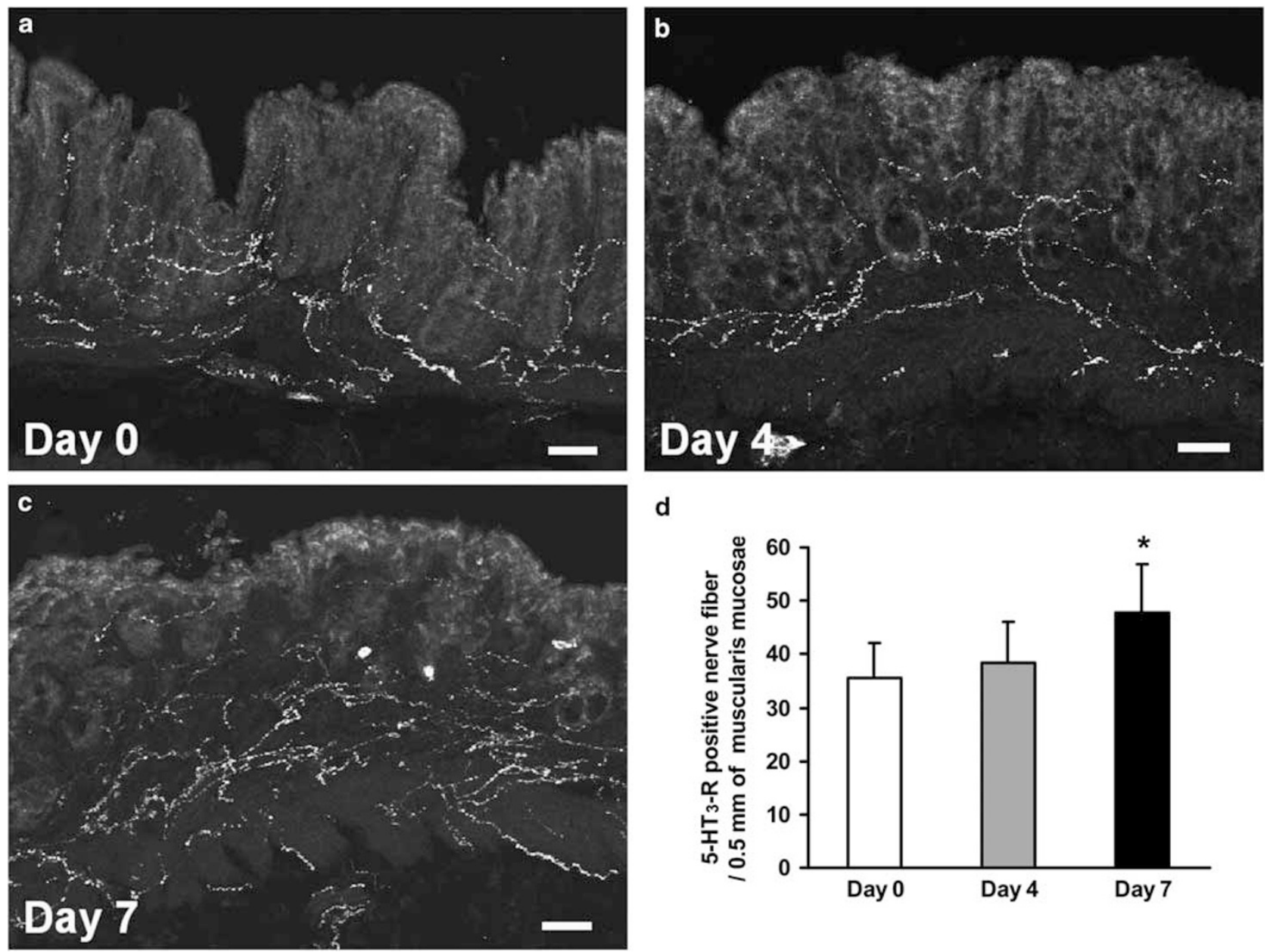

d

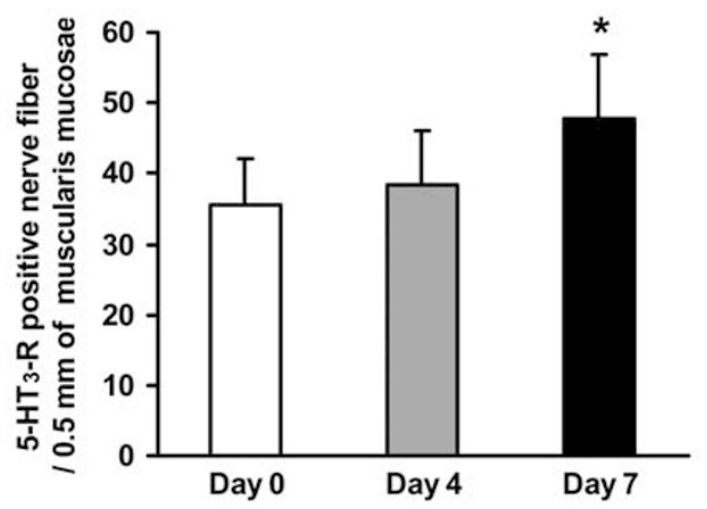

Figure 6 Mucosal 5- $\mathrm{HT}_{3}$ receptor-immunopositive neurons increased in DSS-induced colitis model mouse rectum. Confocal images showing localization of $5-\mathrm{HT}_{3}$ receptor-immunopositive neurons in the mucosa of mice treated with DSS for (a) 0 , (b) 4 , and (c) 7 days. (d) The numbers of 5- $\mathrm{HT}_{3}$ receptorimmunopositive nerve fibers were increased in the mucosa of DSS-treated mice on day 7 . The asterisk $\left(^{*}\right)$ denotes values that are significantly different from the data on day 0 by Bonferroni correction $\left({ }^{*} P<0.05\right)$. Scale bars are $40 \mu \mathrm{m}$.

immunohistochemical analysis on days 0,4 , and 7 of DSS treatment. Consistent with previous findings in experimental colitis model animals and IBD patients, ${ }^{12,16,17}$ SERT expression gradually decreased during DSS treatment. Inflammation has been associated with an increase in the number of 5 -HT-positive cells in mouse mucosa on day 5 of $5 \%$ DSS treatment. ${ }^{16}$ Faure et $a l^{32}$ reported increased expression of TPH-1 mRNA in the mucosa of patients with colonic inflammation. We found that the numbers of 5-HT- and TPH-1-immunopositive cells were significantly increased on day 7 but not on day 4. It is suggested that increased 5-HT content on day 4 depends on low SERT expression. High numbers of 5-HT/TPH-1-immunopositive cells and low SERT expression resulted in increased 5-HT content on day 7. However, we did not observe a significant difference in 5-HT content between days 4 and 7 of DSS treatment. We therefore speculate that a compensatory mechanism, such as an organic cation transporter contributing to the inactivation of 5-HT when SERT is absent or deficient, could be operative. ${ }^{33,34}$
We identified a few $5-\mathrm{HT}_{3}$ receptor- and abundant $5-\mathrm{HT}_{4}$ receptor-immunopositive cell bodies in submucosal and myenteric plexus. We therefore speculate that $5-\mathrm{HT}_{3}$ receptor-immunopositive nerve fibers projecting to the rectal mucosa are mainly extrinsic nerve fibers and that $5-\mathrm{HT}_{4}$ receptor-immunopositive nerve fibers in the mucosa are intrinsic. Double-labeling experiments using specific neurochemical markers were performed to characterize the nerve fibers that express $5-\mathrm{HT}_{3}$ and $5-\mathrm{HT}_{4}$ receptors projecting to the mucosa. We used NeuN as a marker for myenteric IPANs and substance $\mathrm{P}$ as a marker for excitatory motor neurons and myenteric IPANs in the muscle layers. ${ }^{35,36}$ $5-\mathrm{HT}_{4}$ and $5-\mathrm{HT}_{3}$ receptor immunoreactivities were colocalized with NeuN-immunopositive cell bodies and/or substance P-immunopositive neurons in the myenteric plexus. Next, we used two neuropeptides (CGRP and substance P) as markers for spinal afferent neurons and IPANs in the mucosa. ${ }^{30,36}$ 5- $\mathrm{HT}_{4}$ receptor-immunopositive nerve fibers strongly colocalized with the neuropeptides, but only about half of the 

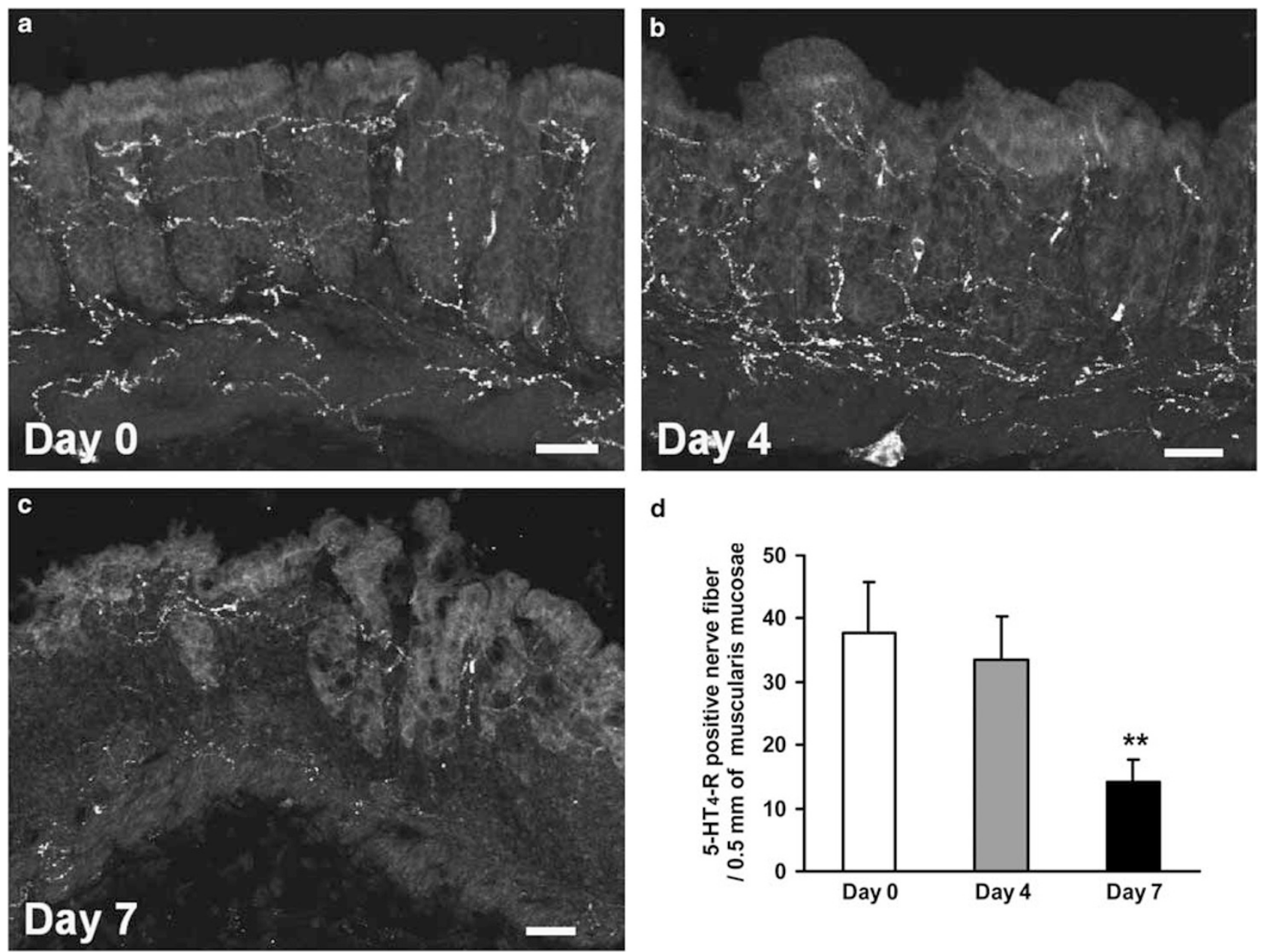

\section{d}

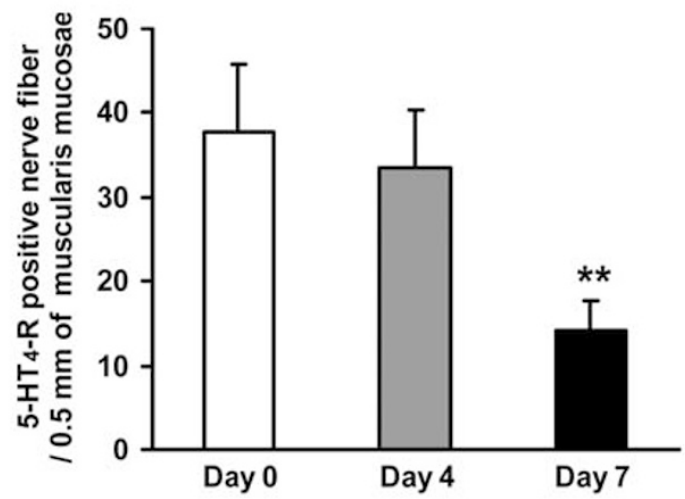

Figure 7 Numbers of mucosal $5-\mathrm{HT}_{4}$ receptor-immunopositive neurons decreased in DSS-induced colitis model mouse rectum. Confocal images showing localization of $5-\mathrm{HT}_{4}$ receptor-immunopositive neurons in the mucosa of mice treated with DSS for (a) 0 , (b) 4 , and (c) 7 days. (d) The number of 5- $\mathrm{HT}_{4}$ receptor-immunopositive nerve fibers significantly decreased in DSS-treated mice mucosa on day 7 . Confocal images showing localization of 5 - $\mathrm{HT}_{4}$ receptor-immunopositive neurons in the submucosal layer of mice treated with DSS for (e) 0 and (f) 7 days. (g) The number of 5-HT 4 receptorimmunopositive neurons in the submucosal layer of DSS-treated mice. The number of $5-\mathrm{HT}_{4}$ receptor-immunopositive nerve fibers emerging from submucosal cell bodies significantly decreased in the mucosa of DSS-treated mice on day 7 . The asterisk ${ }^{*}$ ) denotes values that are significantly different from data on day 0 by Bonferroni correction ( $\left.{ }^{* * P}<0.01\right)$. Scale bars are $40 \mu \mathrm{m}(\mathbf{a}-\mathbf{c})$ and $10 \mu \mathrm{m}$ (e and f).

$5-\mathrm{HT}_{3}$ receptor-immunopositive nerve fibers colocalized with the neuropeptides in the mucosa. It is well known that $5-\mathrm{HT}_{3}$ receptors are expressed in peripheral endings of vagal afferent nerve fibers in the mucosa. ${ }^{37}$ The immunohistochemical observations in the previous studies show that $5-\mathrm{HT}_{4}$ receptors are expressed by submucosal IPANs, myenteric IPANs, and myenteric excitatory motor neurons. ${ }^{38,39} \mathrm{We}$ therefore speculate that $5-\mathrm{HT}_{3}$ receptor nerve fibers projecting to the rectal mucosa are mainly extrinsic spinal and vagal afferent nerve fibers and that $5-\mathrm{HT}_{4}$ receptor nerve fibers in the mucosa are myenteric and submucosal IPANs.

Interestingly, numbers of $5-\mathrm{HT}_{4}$ receptor-expressing nerve fibers in the mucosa gradually decreased during DSS treatment. We speculated that this phenomenon results from DSS-induced inflammatory damage to the submucosal layers. In this study, inflammatory cell migration was observed after
7 days of DSS treatment in both the mucosa and the submucosal layer of the rectum. At this time point, the numbers of $5-\mathrm{HT}_{4}$ receptor-immunopositive axons emerging from cell bodies were decreased drastically in the submucosal layer but unchanged in the myenteric plexus. These results suggest that inflammatory cells injure $5-\mathrm{HT}_{4}$ receptor-immunopositive neurons in the submucosal layer and that numbers of $5-\mathrm{HT}_{4}$ receptor axons in the mucosa subsequently decrease.

The numbers of $5-\mathrm{HT}_{3}$-expressing cell bodies in the myenteric plexus did not change, but the numbers of nerve fibers in the mucosa increased in the inflammatory state. We therefore speculate that the increased $5-\mathrm{HT}_{3}$ receptor-immunopositive nerve fibers in the mucosa are extrinsic spinal and/or vagal afferent nerve fibers. The number of TRPV1immunopositive nerve fibers also increased during DSS treatment. There is some evidence suggesting that 

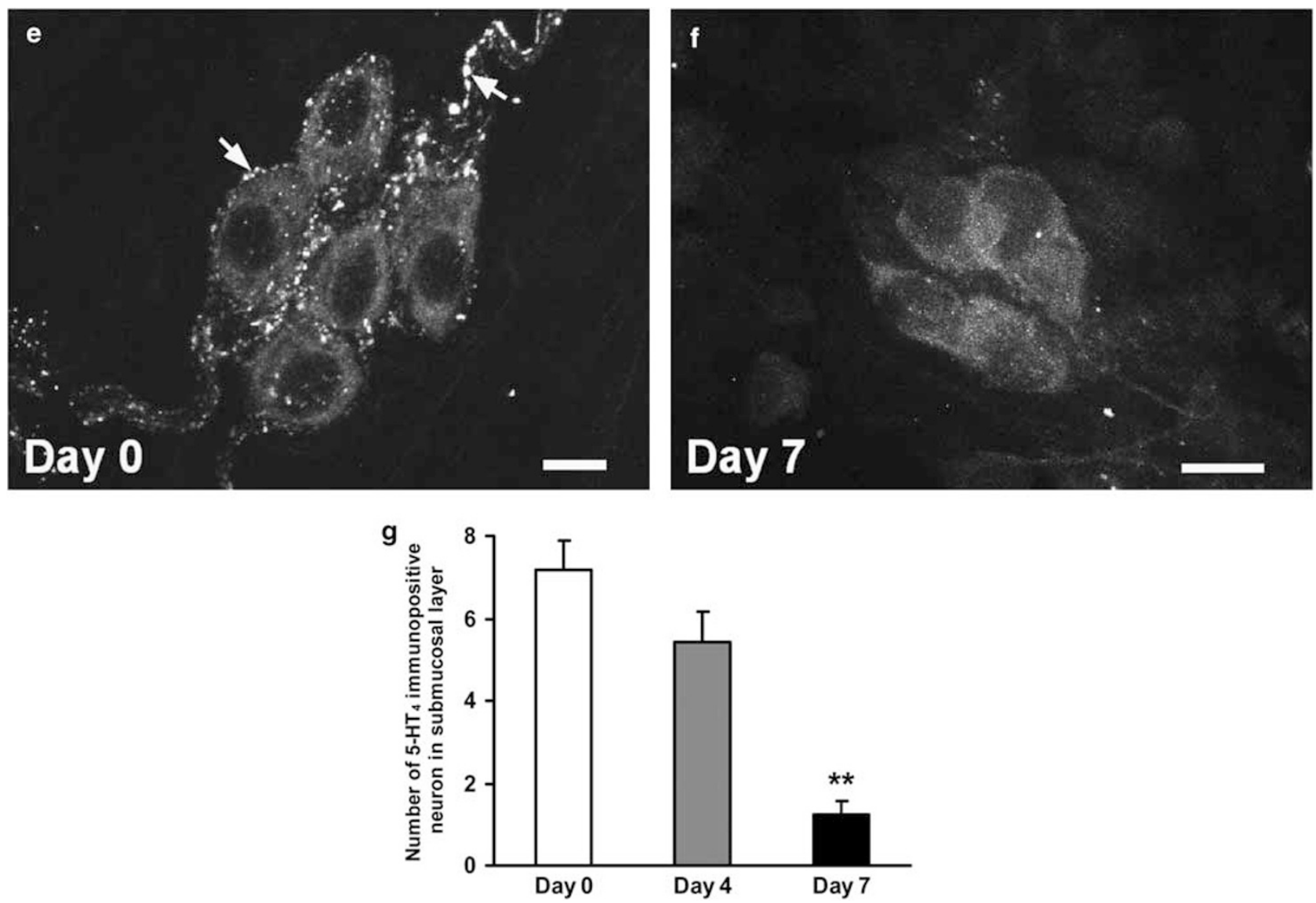

Figure 7 Continued.

neurotrophins, such as nerve growth factor and glial-derived neurotrophic factor, are involved in the overexpression of TRPV1 and $5-\mathrm{HT}_{3}$ receptors. ${ }^{40,41}$ In previous experiments on IBD patients, it has been demonstrated that increased TRPV1 expression is associated with increased nerve growth factor expression in the mucosa. ${ }^{24}$ Neurotrophins are the candidates driving the upregulation of the $5-\mathrm{HT}_{3}$ and TRPV1 expression in the mucosa of DSS-induced colitis model mice.

TRPV1 mRNA expression has been detected in epithelial cells, vascular endothelium, and immune cells among the others. ${ }^{42}$ It has been reported that immune reactive cells, such as mast cells, lymphocytes, and dendritic cells, express TRPV $1 .{ }^{43}$ The results from this study show that some nonneuronal TRPV1 cells contained TNF- $\alpha$. Direct evidence that TNF- $\alpha$ has a role in the pathogenesis of experimental colitis has been obtained in DSS-induced colitis model. ${ }^{44}$ It has been speculated that TRPV1 responds to noxious environmental or inflammatory stimuli, and immune cells such as macrophage-produced interleukins ${ }^{45}$ that, in turn, activate TRPV1-expressing sensory nerves. Future studies will thus likely be focused on the nonneuronal TRPV1 channels involved in intestinal inflammation and on which aspects of the immune system they affect.
Peripheral sensation contributes to the visceral hypersensitivity. ${ }^{46}$ An exaggerated peripheral input to the central nervous system induces visceral hypersensitivity in a peripheral inflammatory state such as IBD. Extrinsic afferent (vagal and spinal) neurons contribute to the pathophysiology of visceral pain. Our recent and previous immunohistochemical findings suggest that the TRPV1 channels located in mouse mucosa are extrinsic spinal afferent neurons $^{30}$ and that $5-\mathrm{HT}_{3}$ receptor-immunopositive nerve fibers are mainly EPANs. It is well known that TRPV1 channels and $5-\mathrm{HT}_{3}$ receptors have a key role in visceral hypersensitivity; indeed, a TRPV1 antagonist-attenuated increased the VMR to CRD following TNBS treatment in rats ${ }^{47}$ and a $5-\mathrm{HT}_{3}$ antagonist inhibited visceral hypersensitivity in acid-induced colitis model rats. ${ }^{20,48}$ Moreover, a 5- $\mathrm{HT}_{3}$ antagonist partially reversed capsaicin-induced rectal hypersensitivity in humans, suggesting that $5-\mathrm{HT}_{3}$ receptors are involved in the transmission of nociceptive information from the rectum via TRPV1 nerve fibers. ${ }^{27}$ In this study, we confirmed the involvement of TRPV1 channels and/or $5-\mathrm{HT}_{3}$ receptors in visceral hypersensitivity using DSS-induced experimental colitis model mice. Phillis et al ${ }^{49}$ reported that a TRPV1 antagonist inhibited mechanosensitivity and 

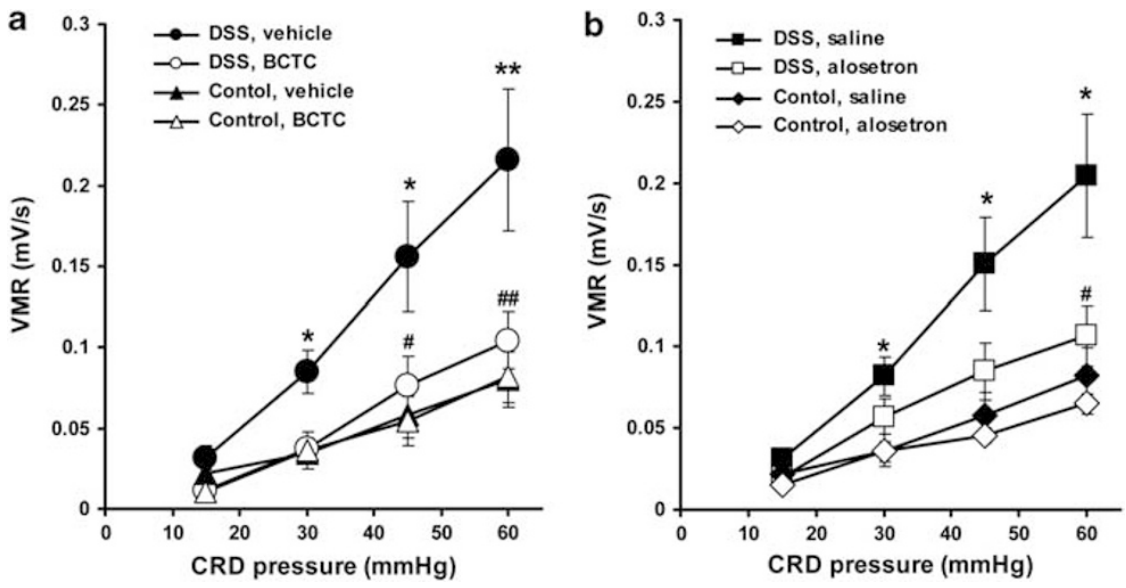

Figure 8 Effects of (a) the TRPV1 antagonist BCTC and (b) the 5-HT 3 receptor antagonist alosetron against DSS-induced visceral hypersensitivity. Abdominal EMG response to CRD in mice treated with DSS for 7 days. Under this experimental condition (see Materials and Methods), the distension mainly stimulates the rectal area corresponding to the area used for immunohistochemical study. Pretreatment with BCTC ( $20 \mathrm{mg} / \mathrm{kg}$, i.p.) and alosetron ( $3 \mathrm{mg} / \mathrm{kg}$, p.o.) significantly attenuated DSS-induced visceral hyperalgesia. The asterisk $\left.{ }^{*}\right)$ denotes values that are significantly different from the data for the control vehicle-treated group $\left({ }^{*} P<0.05,{ }^{* *} P<0.01\right)$. ${ }^{\#}$ denotes values that are significantly different from the data for the DSS vehicle-treated group $\left({ }^{\#} P<0.05\right.$, $\# \#<0.01)$.

spontaneous discharge in rat colonic afferents from inflammatory tissue but did not affect the discharge in afferents from healthy tissue. Consistent with this finding, the TRPV1 antagonist BCTC significantly attenuated the VMR to CRD only in DSS-treated mice, indicating an inducible role for TRPV1 in nociceptive colonic afferents in pathological states. This functional result paralleled immunohistochemical alterations of neuronal and nonneuronal TRPV1 channels and neuronal $5-\mathrm{HT}_{3}$ receptor expression in the inflammatory state. Thus, it is suggested that increased TRPV1 expression and $5-\mathrm{HT}_{3}$ receptor-immunopositive nerve fibers in the mucosa are correlated with visceral hypersensitivity 7 days after DSS treatment.

In conclusion, this is the first comprehensive immunohistochemical study to describe alterations to the expression of $5-\mathrm{HT}_{3}$ and $5-\mathrm{HT}_{4}$ receptors and TRPV1 channels in the mucosa of experimental colitis model animals. The numbers of $5-\mathrm{HT}_{3}$ receptor- and TRPV1-expressing nerve fibers were increased in the mucosa on day 7 of DSS treatment. On the other hand, numbers of $5-\mathrm{HT}_{4}$ receptor-expressing nerve fibers were decreased on day 7. A TRPV1 antagonist and a 5- $\mathrm{HT}_{3}$ receptor antagonist attenuated visceral hyperalgesia to the control level in a DSS-induced colitis model. These results suggest that high $5-\mathrm{HT}_{3}$ and TRPV1 expression in the mucosa contributed to the visceral hypersensitivity in colitis model mice. Furthermore, we clearly observed nonneuronal TRPV1 immunoreactivity in the mucosa of DSS-induced colitis model mice. These novel results may be related to the intestinal inflammation. In fact, anti-inflammatory effects of TRPV1 and 5- $\mathrm{HT}_{3}$ antagonists in colitis model animals have been reported. ${ }^{50,51} 5-\mathrm{HT}_{4}$ agonists promote enteric neuron survival and/or neurogenesis in of the mouse enteric nervous system $^{52}$ and inhibit postoperative ileus through an anti- inflammatory effect. ${ }^{53}$ Although we have shown the timedependent alteration of $5-\mathrm{HT}_{3}$ and $5-\mathrm{HT}_{4}$ receptors and TRPV1, the involvement of these alterations in the progression of inflammation remains to be determined.

Supplementary Information accompanies the paper on the Laboratory Investigation website (http://www.laboratoryinvestigation.org)

\section{ACKNOWLEDGEMENTS}

We thank Tomohiko Makiyama (Chiba University) for the Western blot analysis. This work was supported in part by Grants-in-Aid for Scientific Research from the Ministry of Education, Science, Sports, an Culture of Japan (no. 20790075 and 21590100) and Uehara Memorial Foundation.

\section{DISCLOSURE/CONFLICT OF INTEREST}

The authors declare no conflict of interest.

1. Strober W, Fuss I, Mannon P. The fundamental basis of inflammatory bowel disease. J Clin Invest 2007:117:514-521.

2. De Schepper HU, De Man JG, Moreels TG, et al. Gastrointestinal sensory and motor disturbances in inflammatory bowel disease-clinical relevance and pathophysiological mechanisms. Aliment Pharmacol Ther 2008;27:621-637.

3. Rao SS, Read NW, Davison PA, et al. Anorectal sensitivity and responses to rectal distention in patients with ulcerative colitis. Gastroenterology 1987;93:1270-1275.

4. Chang L, Munakata J, Mayer EA, et al. Perceptual responses in patients with inflammatory and functional bowel disease. Gut 2000;47:497-505.

5. Bernstein $C N$, Niazi $N$, Robert $M$, et al. Rectal afferent function in patients with inflammatory and functional intestinal disorders. Pain 1996;66:151-161.

6. Furness JB, Jones $C$, Nurgali $K$, et al. Intrinsic primary afferent neurons and nerve circuits within the intestine. Prog Neurobiol 2004 72:143-164.

7. Gershon MD. Nerves, reflexes, and the enteric nervous system: pathogenesis of the irritable bowel syndrome. J Clin Gastroenterol 2005;39:S184-S193.

8. Walther DJ, Peter JU, Bashammakh S, et al. Synthesis of serotonin by a second tryptophan hydroxylase isoform. Science 2003;299:76. 
9. Cote $\mathrm{F}$, Thevenot $\mathrm{E}$, Fligny $\mathrm{C}$, et al. Disruption of the nonneuronal tph1 gene demonstrates the importance of peripheral serotonin in cardiac function. Proc Natl Acad Sci USA 2003;100:13525-13530.

10. Wade PR, Chen J, Jaffe B, et al. Localization and function of a 5-HT transporter in crypt epithelia of the gastrointestinal tract. J Neurosci 1996;16:2352-2364.

11. Bishop $A E$, Pietroletti $R$, Taat $C W$, et al. Increased populations of endocrine cells in Crohn's ileitis. Virchows Arch A Pathol Anat Histopathol 1987;410:391-396.

12. Coates MD, Mahoney CR, Linden DR, et al. Molecular defects in mucosal serotonin content and decreased serotonin reuptake transporter in ulcerative colitis and irritable bowel syndrome. Gastroenterology 2004;126:1657-1664.

13. El-Salhy M, Danielsson A, Stenling R, et al. Colonic endocrine cells in inflammatory bowel disease. J Intern Med 1997;242:413-419.

14. Ghia JE, Li N, Wang $\mathrm{H}$, et al. Serotonin has a key role in pathogenesis of experimental colitis. Gastroenterology 2009;137:1649-1660.

15. Bischoff SC, Mailer R, Pabst $\mathrm{O}$, et al. Role of serotonin in intestinal inflammation: knockout of serotonin reuptake transporter exacerbates 2,4,6-trinitrobenzene sulfonic acid colitis in mice. Am J Physiol Gastrointest Liver Physiol 2009;296:G685-G695.

16. Bertrand PP, Barajas-Espinosa A, Neshat S, et al. Analysis of real-time serotonin (5-HT) availability during experimental colitis in mouse. Am J Physiol Gastrointest Liver Physiol 2010;298:G446-G455.

17. Linden DR, Chen JX, Gershon MD, et al. Serotonin availability is increased in mucosa of guinea pigs with TNBS-induced colitis. Am J Physiol Gastrointest Liver Physiol 2003;285:G207-G216.

18. Gershon MD, Tack J. The serotonin signaling system: from basic understanding to drug development for functional Gl disorders. Gastroenterology 2007;132:397-414.

19. De Giorgio R, Barbara G, Furness JB, et al. Novel therapeutic targets for enteric nervous system disorders. Trends Pharmacol Sci 2007; 28:473-481.

20. Choi YD, Sung TS, Kim HJ, et al. Increased 5-hydroxytryptamine mediates post-inflammatory visceral hypersensitivity via the 5hydroxytryptamine 3 receptor in rats. Dig Dis Sci 2008;53:2909-2916.

21. Greenwood-Van Meerveld B, Venkova K, Hicks G, et al. Activation of peripheral 5-HT receptors attenuates colonic sensitivity to intraluminal distension. Neurogastroenterol Motil 2006;18:76-86.

22. Holzer P. Sensory neurone responses to mucosal noxae in the upper gut: relevance to mucosal integrity and gastrointestinal pain Neurogastroenterol Motil 2002;14:459-475.

23. Caterina MJ, Schumacher MA, Tominaga $M$, et al. The capsaicin receptor: a heat-activated ion channel in the pain pathway. Nature 1997;389:816-824.

24. Akbar A, Yiangou $\mathrm{Y}$, Facer $\mathrm{P}$, et al. Expression of the TRPV1 receptor differs in quiescent inflammatory bowel disease with or without abdominal pain. Gut 2010;59:767-774.

25. Yiangou $\mathrm{Y}$, Facer $\mathrm{P}$, Dyer $\mathrm{NH}$, et al. Vanilloid receptor 1 immunoreactivity in inflamed human bowel. Lancet 2001 357:1338-1339.

26. Sugiuar T, Bielefeldt K, Gebhart GF. TRPV1 function in mouse colon sensory neurons is enhanced by metabotropic 5-hydroxytryptamine receptor activation. J Neurosci 2004;24:9521-9530.

27. Gonlachanvit S, Fongkam P, Wittayalertpanya S, et al. Red chili induces rectal hypersensitivity in healthy humans: possible role of $5 \mathrm{HT}_{-}$ receptors on capsaicin-sensitive visceral nociceptive pathways. Aliment Pharmacol Ther 2007;26:617-625.

28. Murthy SN, Cooper HS, Shim H, et al. Treatment of dextran sulfate sodium-induced murine colitis by intracolonic cyclosporine. Dig Dis Sci 1993;38:1722-1734.

29. Theiss AL, Vijay-Kumar M, Obertone TS, et al. Prohibitin is a novel regulator of antioxidant response that attenuates colonic inflammation in mice. Gastroenterology 2009;137:199-208.

30. Matsumoto K, Hosoya T, Tashima K, et al. Distribution of transient receptor potential vanilloid 1 channel-expressing nerve fibers in mouse rectal and colonic enteric nervous system: relationship to peptidergic and nitrergic neurons. Neuroscience 2011;172:518-534.

31. Matsumoto K, Kurosawa E, Terui $H$, et al. Localization of TRPV1 and contractile effect of capsaicin in mouse large intestine: high abundance and sensitivity in rectum and distal colon. Am J Physiol Gastrointest Liver Physiol 2009;297:G348-G360.

32. Faure $C$, Patey N, Gauthier $C$, et al. Serotonin signaling is altered in irritable bowel syndrome with diarrhea but not in functional dyspepsia in pediatric age patients. Gastroenterology 2010;139:249-258.

33. Chen JJ, Li Z, Pan H, et al. Maintenance of serotonin in the intestinal mucosa and ganglia of mice that lack the high-affinity serotonin transporter: abnormal intestinal motility and the expression of cation transporters. J Neurosci 2001;21:6348-6361.

34. Schmitt A, Mossner R, Gossmann A, et al. Organic cation transporter capable of transporting serotonin is up-regulated in serotonin transporter-deficient mice. J Neurosci Res 2003;71:701-709.

35. Furness JB. The Enteric Nervous System. Oxford University Press: Oxford, 2006

36. Chiocchetti R, Poole DP, Kimura $H$, et al. Evidence that two forms of choline acetyltransferase are differentially expressed in subclasses of enteric neurons. Cell Tissue Res 2003;311:11-22.

37. Glatzle J, Sternini $\mathrm{C}$, Robin $\mathrm{C}$, et al. Expression of $5-\mathrm{HT}_{3}$ receptors in the rat gastrointestinal tract. Gastroenterology 2002;123:217-226.

38. Liu M, Geddis MS, Wen $\mathrm{Y}$, et al. Expression and function of $5-\mathrm{HT}_{4}$ receptors in the mouse enteric nervous system. Am J Physiol Gastrointest Liver Physiol 2005;289:G1148-G1163.

39. Poole DP, Xu B, Koh SL, et al. Identification of neurons that express 5hydroxytryptamine4 receptors in intestine. Cell Tissue Res 2006;325:413-422.

40. Amaya F, Shimosato G, Nagano M, et al. NGF and GDNF differentially regulate TRPV1 expression that contributes to development of inflammatory thermal hyperalgesia. Eur J Neurosci 2004;20:2303-2310.

41. Zeng F, Watson RP, Nash MS. Glial cell-derived neurotrophic factor enhances synaptic communication and 5-hydroxytryptamine 3a receptor expression in enteric neurons. Gastroenterology 2010;138:1491-1501.

42. Gunthorpe MJ, Szallasi A. Peripheral TRPV1 receptors as targets for drug development: new molecules and mechanisms. Curr Pharm Des 2008;14:32-41.

43. Khairatkar-Joshi N, Szallasi A. TRPV1 antagonists: the challenges for therapeutic targeting. Trends Mol Med 2009;15:14-22.

44. Urthy $\mathrm{S}$, Cooper HS, Yoshitake $\mathrm{H}$, et al. Combination therapy of pentoxifylline and TNF-a monoclonal antibody in dextran sulphateinduced mouse colitis. Aliment Pharmacol Ther 1999;13:251-260.

45. Southall MD, Li T, Gharibova LS, et al. Activation of epidermal vanilloid receptor-1 induces release of proinflammatory mediators in human keratinocytes. J Pharmacol Exp Ther 2003;304:217-222.

46. Gebhart GF. Pathobiology of visceral pain: molecular mechanisms and therapeutic implications IV. Visceral afferent contributions to the pathobiology of visceral pain. Am J Physiol Gastrointest Liver Physiol 2000;278:G834-G838.

47. Miranda A, Nordstrom E, Mannem A, et al. The role of transient receptor potential vanilloid 1 in mechanical and chemical visceral hyperalgesia following experimental colitis. Neuroscience 2007 148:1021-1032.

48. Miranda A, Peles S, McLean PG, et al. Effects of the 5-HT3 receptor antagonist, alosetron, in a rat model of somatic and visceral hyperalgesia. Pain 2006;126:54-63.

49. Phillis BD, Martin CM, Kang D, et al. Role of TRPV1 in high-threshold rat colonic splanchnic afferents is revealed by inflammation. Neurosci Lett 2009;459:57-61.

50. Kihara N, de la Fuente SG, Fujino $\mathrm{K}$, et al. Vanilloid receptor-1 containing primary sensory neurons mediate dextran sulphate sodium induced colitis in rats. Gut 2003;52:713-719.

51. Mousavizadeh K, Rahimian R, Fakhfouri G, et al. Anti-inflammatory effects of 5-HT receptor antagonist, tropisetron on experimental colitis in rats. Eur J Clin Invest 2009;39:375-383.

52. Liu MT, Kuan $\mathrm{YH}$, Wang J, et al. 5- $\mathrm{HT}_{4}$ receptor-mediated neuroprotection and neurogenesis in the enteric nervous system of adult mice. J Neurosci 2009;29:9683-9699.

53. Tsuchida $Y$, Hatao F, Fujisawa M, et al. Neuronal stimulation with 5hydroxytryptamine 4 receptor induces anti-inflammatory actions via \{alpha\}7nACh receptors on muscularis macrophages associated with postoperative ileus. Gut 2011;60:638-647. 